Research Article

\title{
Intelligent Tourism Personalized Recommendation Based on Multi-Fusion of Clustering Algorithms
}

\author{
HongYan Liang (iD \\ Xinyang Vocational and Technical College, Xinyang 464000, China \\ Correspondence should be addressed to HongYan Liang; lianghongyan123@xyvtc.edu.cn
}

Received 21 October 2021; Revised 4 November 2021; Accepted 18 November 2021; Published 17 December 2021

Academic Editor: Qiangyi Li

Copyright (c) 2021 HongYan Liang. This is an open access article distributed under the Creative Commons Attribution License, which permits unrestricted use, distribution, and reproduction in any medium, provided the original work is properly cited.

\begin{abstract}
Actual tourism mining models are often used to discover potential information in documents, but tourism models without human knowledge often produce unexplainable topics. This paper combines big data technology to build a personalized recommendation system for smart tourism, model the contextual information usage ontology under the tourism information system, and give the association between various ontologies. Then, this paper uses a matrix to describe each discrete attribute and interval attribute and uses a vector to model the user's preferences. In addition, this paper constructs an intelligent recommendation system based on the actual needs of travel recommendation and verifies the system in combination with experimental research. Through experimental analysis, it can be known that the intelligent tourism personalized recommendation system based on big data technology proposed in this paper has a high practical effect.
\end{abstract}

\section{Introduction}

With the popularity and popularization of smart mobile devices, more and more people will use social networking sites to post photos, post videos, post comments, check in, etc., when traveling, to record their journeys, to facilitate memories, or to share with others. These uploaded and shared contents all provide a wealth of resources for people to study the recommendation of tourist attractions. The user's personal preferences are hidden in these resources uploaded by the user. Through analysis and statistics, it is possible to dig out the user's preferences and the characteristics of the scenic spot itself, enrich the data source for user similarity calculation, and thereby provide the possibility to improve the recommendation effect of the collaborative filtering recommendation algorithm. At present, crawling and analyzing travel data uploaded by users from travel websites and researching personalized recommendations for tourist attractions has become a new research hotspot [1].

In the development of computing technology, computing models play an extremely critical role. Therefore, computing models have gradually made computers more generalized, not just for use in laboratories but for popular life. Moreover, any computing model is proposed, which will inevitably promote the development of corresponding computing technology. Just as host computing promotes the upgrading of various computer equipment, desktop computing provides technical support for the development of visualization and other technologies [2]. However, these computing modes make people perform complex operations and complete various settings to obtain the required information in the process of using computers, so computer users need strong operating capabilities. It was not until the new development of computing mode and the update of computer hardware and software equipment that computer operations became relatively simple and began to be popularized and widely used. However, as the needs of the times change, the computing model is constantly changing accordingly. With the accelerating pace of people's lives nowadays, people want to free themselves from tedious computer operations and use computers conveniently and autonomously anytime, anywhere, and get the digital services they want. Pervasive computing is the computing model produced for people to realize these ideas [3]. 
With the increase in the number of travel websites, the accumulation of content over time, and the increasing coverage, how to better grasp the needs of users and attract users' attention has become the key task of each portal website. The topic model that integrates knowledge can generate topics more in line with user interests based on prior knowledge. The development of tourism is not only the attraction of scenic spots to tourists but also whether it is convenient for users to travel, eat, live, and play. Before traveling, tourists will search for relevant information about the attractions they go to, choose a place to live, and view comments related to the attractions. Therefore, a good smart tourism search engine is very important.

This article combines big data technology to construct a personalized recommendation system for smart tourism, to improve the personalized service of tourism, and to improve the travel experience of tourists.

\section{Related Work}

In real life, it is necessary to make recommendations for group users in many cases, for example, a few people go out to eat, watch a movie, or go shopping in groups. Although group recommendations appear later than individual recommendations, with the emergence of more and more group users' demand for personalized information, many scholars have conducted research on how to provide group recommendations.

The model studied in the literature [4] first recommends the individual separately. Then, taking into account the possible special attributes of individuals in the group, such as children and the disabled, when the individual recommendation results are integrated, these special individuals are assigned relatively large weights, so that the final group results will be more biased towards these people. Literature [5] proposed a new collaborative filtering recommendation system, which aims to recommend items for user groups, not for individuals. The system first uses a collaborative filtering algorithm to make recommendations for each member of the group and then finds the same items from the recommendation list to build a group recommendation list. This method can use individual recommendation methods to achieve group recommendation. However, only the simple addition of individual recommendation results cannot meet the actual needs of real life. For example, for travel route recommendation, it is recommended that a route contains scenic spots and edges between scenic spots, which cannot be obtained through comprehensive recommendation results. Therefore, this type of method is not suitable for travel route recommendation.

Literature [6] developed a group recommendation system, which plays music to the group by learning the content that users do not want to hear and avoids those songs. The system analyzes the aspects that the user is not interested in and determines which solutions the user is not satisfied with and assumes that the remaining solutions are satisfactory. Literature [7] designed a system to recommend restaurants for group users. It first calculates the personal preference of each person in the group for each restaurant and then takes the average of user preferences to represent the group's preference for restaurants and based on this recommends restaurants to groups. Literature [8] studied a system for recommending hotels for groups using the least painful method, in which the recommended hotels will not make members dissatisfied. Literature [9] first predicts the score of each member through the method of collaborative filtering and then uses the average method to aggregate the respective prediction scores of the group members to form the group's prediction score for the item, thereby generating recommendations. Literature [9] uses the user's social relationship and behavior information to recommend movies for independent groups. This method takes into account the interaction between group members and helps people with common activities to make decisions in conflict situations. Literature [10] proposed a group tourism activity recommendation system. This method is based on manual statistics, content, and preference filtering; obtains group recommendations from the personal preferences of each individual user; and uses application aggregation, crossover, and incremental communication to calculate group. The group list preference has achieved the purpose of group recommendation. Literature [11] confirmed through experiments that group recommendation should meet the preferences of all group members as much as possible. In recommendation, voting mechanism and negotiation mechanism can be used to extract group preferences and make recommendations for the group. The experimental results show that the voting mechanism can satisfy the preferences of all members of the group better than the negotiation mechanism. Literature [12] proposes a technical framework for recommending routes to groups. This method first uses clustering algorithms to mine user groups and user preferences based on the user's check-in records. Then, group preferences and related constraints are integrated to recommend travel routes that meet their needs for group users. However, this method requires group mining first and cannot recommend for people who do not belong to the same group. Literature [13] analyzed the characteristics and attributes of the members of the group, combined with the social influence theory when gathering group preferences, and made recommendations for the group based on this. Literature [14] proposed a group travel route preference model, which analyzes the user's feedback information and obtains the user's preference from it and uses the least pain method to recommend a suitable travel route for the group. Although these early studies have achieved good recommendations, the travel routes recommended by these methods cannot guarantee the maximum satisfaction of the group and the minimum difference in satisfaction between individuals.

\section{Analysis and Design of Intelligent Tourism Recommendation Subsystem Based on Big Data Technology}

After analyzing the context under the application of the tourism information system, in order to clearly describe it in 
a formal way, we use ontology as a tool to model the contextual information of the tourism environment.

Based on the above analysis of tourism context information, the tourism context ontology model should contain four top-level ontologies, namely, time ontology (owl: Time), location ontology (owl: Location), user ontology (owl: User), and other contextual ontology (owl: Other). Under these ontologies, several special ontologies under the environment of tourist attractions are derived. The relationship between them and their respective top-level ontologies is the subclass relationship (rdfs: subClassOf). The following will introduce in detail some of the ontologies included in the ontology.

According to the above analysis, five subtype ontologies can be derived, namely, year ontology (owl: Year), month ontology (owl: Month), week ontology (owl: Week), date ontology (owl: Date), and time ontology (owl: Time Period). Based on the above analysis of time context information, the date ontology is divided into weekday (owl: WeekDay), holiday ontology (owl: Holiday), rest weekend (owl: Weekend), and duty day (owl: Duty Day). The time period ontology is divided into daytime ontology (owl: Day Time) and nighttime ontology (owl: Night Time). Among them, the four ontologies weekday, rest weekend, day, and night can also be divided. In order to clearly show the inclusion relationship among the five subtype ontologies derived from the time ontology, we created the object attribute inclusion relationship (rdfs: time_include). In order to clearly show the relationship between the various attributes in the time period, we created two data attributes and two object attributes, namely, the start time (rdfs: start_time), the end time (rdfs: end_time) and the last time (rdfs: last_time), the next time (rdfs: next_time). The time ontology model is shown in Figure 1 [15].

According to the above analysis, the location ontology can derive two subtype ontologies, namely, the inside ontology of tourist attractions and the outside ontology of tourist attractions. The recommendation system is based on the situation and characteristics of each user to provide recommendations that meet their individual needs, so that users can use it easily and will not spend a lot of query time in massive amounts of information. Therefore, obtaining and accurately analyzing the user's preferences and constructing an appropriate preference model have become an important part of the recommendation system.

According to the integrated characteristics of mobile application and context-aware recommendation, the recommendation system of this paper divides user preferences into two categories based on the integration of contextual information, namely, short-term preference and long-term preference. Among them, short-term preference has the characteristics of short update cycle and relatively sensitive to contextual information. Long-term preferences have the characteristics of a long update cycle and relatively stable user habitual preferences.

The attribute information of tourist attractions includes interval attributes such as whether there is parking space, WiFi, travel expense range, travel age range, and distance attributes from the user's location. The situational information also includes discrete information such as weather conditions. It is represented by the following matrix [16]:

$$
\left(\begin{array}{ccc}
a_{11} & \cdots & a_{1 m} \\
\vdots & \ddots & \vdots \\
a_{n_{1}} & \cdots & a_{n m}
\end{array}\right) .
$$
is

Among them, the value range of the $a_{n_{1}}$ interval attribute

$$
\left[\min \left(a_{* l}\right), \max \left(a_{* l}\right), \quad 1 \leq l \leq r\right] .
$$

The value range of discrete attribute $a_{n_{1}}[14]$ is

$$
\cup a_{* l}(r+1 \leq l \leq r+s) .
$$

After the attribute information and context information are represented by a matrix, a set of vectors can be used to represent the user's preference model, which can be represented as $\left.\ll c_{1}, d_{1}, b_{1}\right\rangle, \ldots,\left\langle c_{r}, d_{r}, b_{r}\right\rangle, g_{1}, \ldots, c_{s}>$.

In this article, the more mature recommendation algorithms that have been studied in the traditional Internet are summarized, and their respective advantages and disadvantages are compared. Each algorithm has its application, so recommendation algorithms are not good or bad. In the tourism information mobile application, there are many classifications of tourist attractions, tourist attractions, and service personnel therein. Each tourist attraction category, tourist attractions under the category, and service personnel under the tourist attractions have different attributes. At the same time, the context information of various users under system application is relatively discrete and special. In order to realize personalized recommendation, a recommendation system based on context information must have both the ability to deal with discrete attributes and a small amount of calculation. In a tourism information recommendation system based on situational awareness, if a content-based recommendation method is used, it is necessary to analyze the feature value of the recommended item and calculate its similarity with the user. This method will make the efficiency of recommending information to tourists slow. It cannot be compromised in the calculation of the accuracy and similarity of the recommended information: the method based on collaborative filtering also requires the user's historical browsing data and cannot effectively deal with new tourists, new tourist attractions, and new service personnel-cold start problem. For the above reasons, the recommendation system studied in this paper uses a rule-based recommendation algorithm to recommend tourist attractions and service personnel to tourists.

This system obtains attribute and situational information of tourist users, tourist attractions, and service personnel. Moreover, the system performs matching and recommendation calculations and searches in the rule base and finally outputs the tourist attractions and service personnel sets that the user is most likely to be interested in. The framework of the recommendation system is shown in Figure 2.

The input part of the system includes two parts: the information obtained by the system and the information 


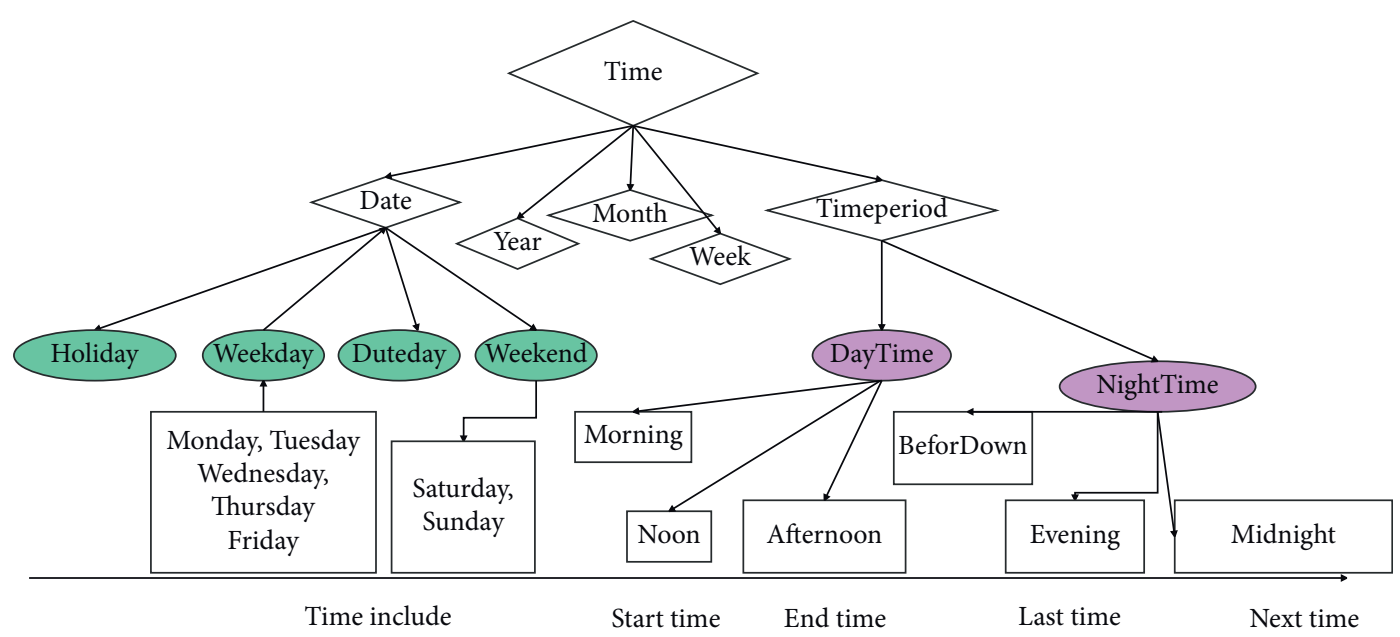

Figure 1: Time ontology model.

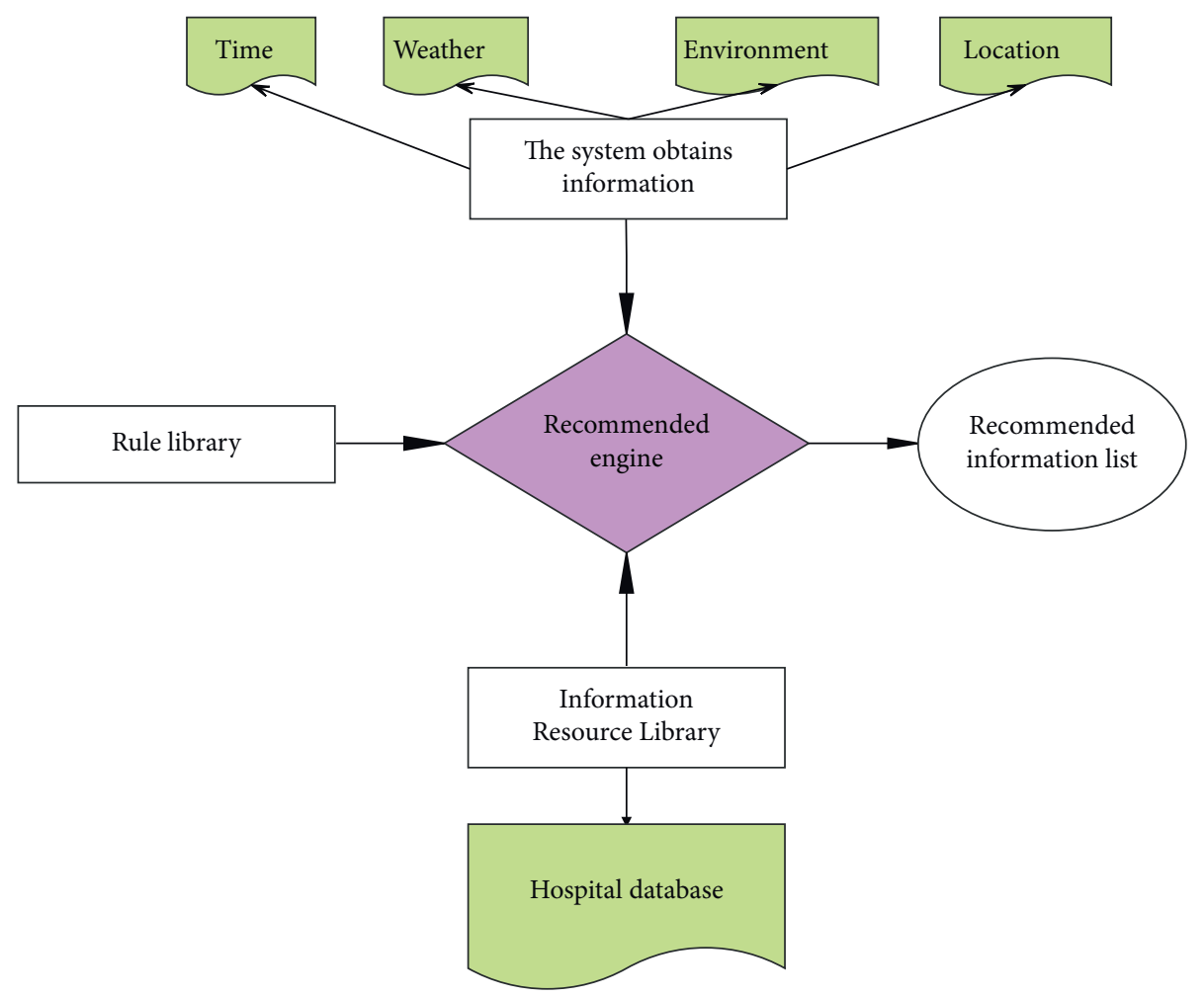

Figure 2: The overall framework of the recommendation system.

resource database. The information obtained by the system includes user attribute information and user context information (time, location, weather, environment). The information resource database includes information on tourist attractions and service personnel, which is the initial candidate set of tourist attractions and service personnel.

Since the results recommended to users need to be balanced among evaluation indicators such as hit rate, diversity, and real-time performance, various types of tourist attractions should be included in the set of results pushed to users. In addition to tourist attraction information related to the user's travel history and service personnel information pushed by time slices, tourist attraction information that can be ordered online can also be added to improve the quality of the results. This recommendation system integrates user attributes and various contextual information of users and matches the categories of tourist attractions, travel agencies, and service personnel. Moreover, it determines the tourist attraction information suitable for the user at a certain time and a certain place and realizes the personalized recommendation for the user. Figure 3 describes the process of this recommendation system.

Because the process of recommending tourist attractions and service personnel is relatively cumbersome, this section 


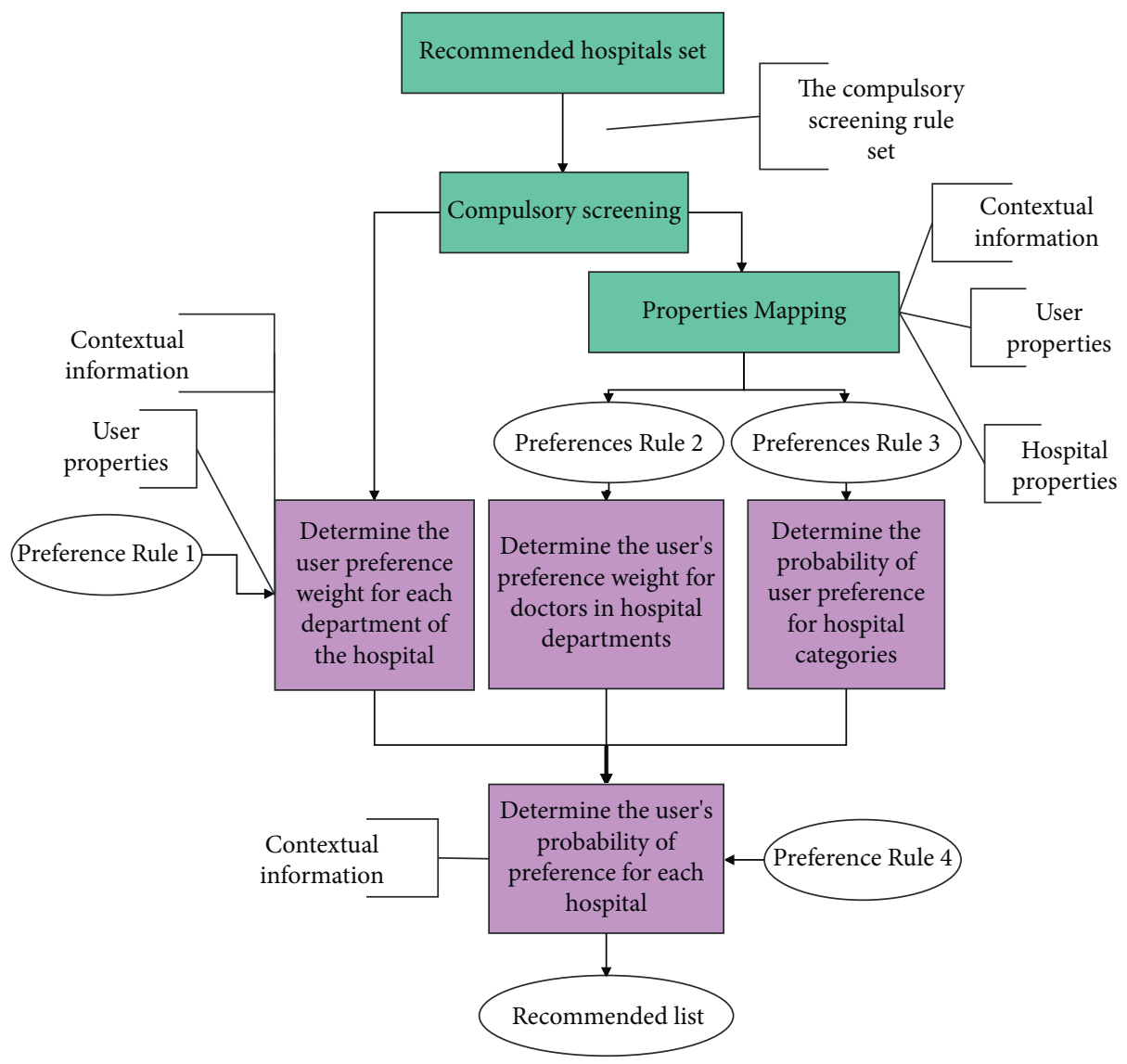

FIGURE 3: Flow chart of travel information recommendation method.

uses examples to explain the detailed process of each link in recommending information to tourists.

The first step is to mandatory screening.

According to the mandatory screening rule set, the algorithm deletes tourist attractions that do not match the current location and time of the tourist user. First, the algorithm calculates the distance between the location information of tourist attractions and the user's current location information and deletes tourist attractions with a distance greater than $D$ (such as $2 \mathrm{~km}$ ) to forcibly narrow the candidate set of tourist attractions. Then, the algorithm extracts the current time and working hours of tourist attractions and deletes tourist attractions that are not open at the current time and $H$ hours from the candidate set (considering the time required for the user to go to tourist attractions) to further narrow the candidate set of tourist attractions. Finally, the algorithm forces the deletion of tourist attractions that the user has browsed or favorited to avoid repeated recommendations. Examples of mandatory screening rules are shown in Table 1 .

The second step is to calculate in parallel to determine the user's preference probability for the tourist attraction category, the user's preference probability for each travel agency in the tourist attraction, and the user's preference probability for the service staff of the tourist attraction travel agency. The following uses a calculation example of the user's preference probability for the category of tourist attractions as an example.
The system calculates the influence of time, weather, environment, and other contextual information on recommended tourist attraction categories, determines the probability of recommending each tourist attraction category, and obtains a recommendation probability table for recommending tourist attraction categories to tourist users. After that, the algorithm combines the personalized information of the tourist to revise the recommendation probability table obtained. Finally, the algorithm combines the revised probability table to obtain the probability of recommending each tourist attraction category for tourist users. The user's preference determination rules for tourist attraction categories are shown in Table 2:

3.1. External-User. For the sake of simplicity, the system uses the weighted average method to calculate the preference probability value $K_{i j}$ of user $i$ for tourist attraction category $j$, as shown in the following formula [17]:

$$
K_{i j}=\frac{1}{3}\left(G_{i j}^{\prime}+A_{i j}^{\prime}+T_{i j}^{\prime}\right) .
$$

In addition, there is some other information that may cause users to choose different types of tourist attractions. The user's preference probability value for tourist attractions, travel agencies and service personnel, user attributes such as age and gender of the tourist, and contextual 
TABLE 1: Examples of mandatory screening rules.

\begin{tabular}{l}
$\begin{array}{l}\text { Screening condition } \\
\begin{array}{c}\text { The algorithm calculates the distance between the user and the tourist attractions based on the user's location } \\
\text { information and deletes tourist attractions with a distance greater than } D \text { from the candidate set } \\
\text { The algorithm extracts the current time and working hours of tourist attractions and deletes tourist attractions } \\
\text { that are not open at the current time from the candidate set }\end{array} \\
\begin{array}{l}\text { Tourist attraction } \\
\text { location }\end{array} \\
\begin{array}{l}\text { The algorithm forcibly deletes tourist attractions that the user has browsed or favorited to avoid repeated } \\
\text { recommendations }\end{array} \\
\text { The algorithm calculates the distance between the user and the tourist attractions based on the user's location } \\
\text { information and deletes tourist attractions with a distance greater than } D \text { from the candidate set }\end{array}$ \\
\hline
\end{tabular}

TABLE 2: Determination rules for tourist attraction categories.

\begin{tabular}{|c|c|c|}
\hline & $\begin{array}{l}\text { Gender- } \\
\text { user }\end{array}$ & $\begin{array}{l}\text { The algorithm assigns the initial recommendation probability Gij to the } \\
\text { tourist attraction category } \mathrm{j} \text { according to the gender } \mathrm{i} \text { and combines the } \\
\text { gender of the tourist user and the electronic log to modify the } \\
\text { recommendation probability }\end{array}$ \\
\hline $\begin{array}{l}\text { Integrate and modify user attributes, contextual } \\
\text { information, and personalized information }\end{array}$ & Age-user & $\begin{array}{l}\text { The algorithm first subdivides the age into different age groups and then } \\
\text { assigns the initial recommendation probability } A_{i j} \text { to the tourist attraction } \\
\text { category } j \text { according to the age group } i\end{array}$ \\
\hline & Time-user & $\begin{array}{l}\text { The algorithm first subdivides the time into different time periods, then } \\
\text { assigns the initial recommendation probability } T_{i j} \text { to the tourist attraction } \\
\text { category } j \text { according to the time period } i \text {, and revises the recommendation } \\
\text { probability to } T_{i j}^{\prime} \text { according to the time of the tourist user }\end{array}$ \\
\hline $\begin{array}{l}\text { Calculate user's short-term preference for tourist } \\
\text { attraction categories }\end{array}$ & $\begin{array}{l}\text { External- } \\
\text { user }\end{array}$ & $\begin{array}{c}\text { The algorithm determines the above two probability values, and } \\
\text { according to the weighted average algorithm, it is concluded that the } \\
\text { probability value of the tourist attraction category } j \text { recommended to } \\
\text { tourist } i \text { is } K_{i j}\end{array}$ \\
\hline
\end{tabular}

information such as time and location may affect the user's choice. Through preference rule 2 and preference rule 3 to modify the probability value, the probability value of tourist users' preference for travel agency and service personnel is obtained.

The third step is to calculate the three preference probability values obtained in parallel in the second step and combine the user's preference for weather information, environmental information, and preference rule 4 to calculate the recommendation probability of each tourist attraction. Finally, according to the recommended rule database, the tourist attractions with higher recommended probability values are recommended to the tourists, and the feedback scores of the tourists are recorded to modify the rules in the rule database.

Through the above determination of the use of the recommendation algorithm, the modeling of user preferences and an overview of the recommendation system process, this section designs and calculates the rule base. Rules are the basis for implementing rule-based recommendation methods, so before using rules for recommendation, we must first solve the problem of rule design and calculation.

In the rule base, the form of the rule is defined as $A \Rightarrow B(P)$, that is, if $A$, then $B$. At the same time, it is accompanied by a probability. In the rule, $A$ represents the attribute or contextual information of the tourist user and $B$ represents the attribute or contextual information of the tourist attraction and service personnel. Probability represents the degree of matching and the probability that tourists prefer a certain type of tourist attraction, a certain tourist attraction, and a certain service person under the situation.
For example, a rule in the rule base: If age $=60$, then $d=$ [0-2000](0.64) means that if the user's age is 60 , then the probability of recommending tourist attractions within 2000 meters away is 0.64 .

The following describes in detail how the rule-based context-aware recommendation system matches the rules in the rule base and how to calculate it.

\subsubsection{Obtain Personalized User Short-Term Preferences.} According to the user's current time, weather, location, and environmental attributes, the algorithm determines the user's short-term preference matrix, and according to the user's preference, after the action of the preference rule set 1 , the matrix is modified to obtain the following matrix:

$$
\left(\begin{array}{cccc}
T_{1} & T_{2} & T_{3} & \cdots \\
W_{1} & W_{2} & W_{3} & \cdots \\
L_{1} & L_{2} & L_{3} & \cdots \\
E_{1} & E_{2} & E_{3} & \cdots
\end{array}\right) .
$$

Among them, $T_{i}, W_{i}, L_{i}$, and $E_{i}$, respectively, represent the user's preference probability for $i$-type tourist attractions under the current time, current weather, current location of the user, and current environment.

The user's recommendation probability ranking for all tourist attractions is based on the following formula [18]:

$$
K_{i j}=\frac{1}{4}\left(T_{i}+W_{i}+E_{i}\right) .
$$

The recommended ranking list of tourist attraction categories is obtained. 


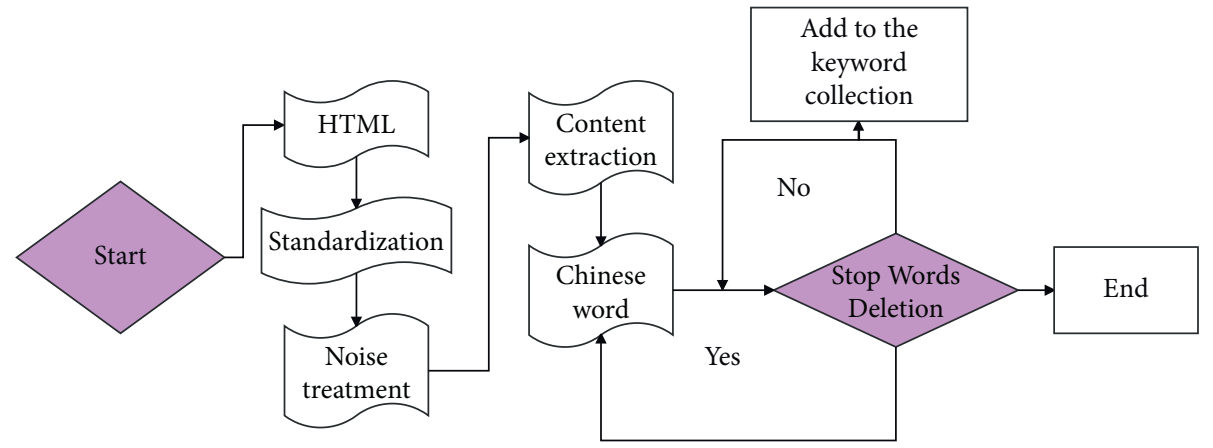

FIgURE 4: Flow chart of information preprocessing.

3.1.2. Obtain User Long-Term Preferences. According to the preference rule set 2 , the user attributes are matched with the rules in the rule base to obtain the preference probability for a travel agency of a tourist attraction:

$$
\left(\begin{array}{ccc}
Q_{11} & \cdots & Q_{1 m} \\
\vdots & \ddots & \vdots \\
Q_{m_{1}} & \cdots & Q_{m n}
\end{array}\right)
$$

Among them, the $m$ row represents the user's $m$ attributes, the $n$ column represents the travel agency of $n$ tourist attractions, and $Q_{i j}$ represents the preference of the user's attribute $i$ to the travel agency $j$ of the tourist attractions. The user's preference weight for tourist attractions and travel agencies can be calculated by the following formula [19]:

$$
X_{j}=\frac{\left(\sum_{i=1}^{n} Q_{i j}\right)}{n} .
$$

According to the preference rule set 3 , the user attributes are matched with the rules in the rule library to obtain the user's preference probability for the service personnel of tourist attractions and travel agencies, and the following matrix is obtained:

$$
\left(\begin{array}{ccc}
q_{11} & \cdots & q_{1 m} \\
\vdots & \ddots & \vdots \\
q_{m_{1}} & \cdots & q_{m n}
\end{array}\right) .
$$

By multiplying the user's preference weight for tourist attraction travel agency calculated by rule set 2 and various attributes with the user's preference probability for tourist attraction travel agency service personnel calculated by rule set 3 and various attributes, the user's preference probability for service personnel attributes is obtained. After that, the preference probability is sorted, and the service staff corresponding to the highest preference probability is the user's long-term preference.

3.1.3. Determine the Recommendation Probability of Each Tourist Attraction. According to rule set 4, each tourist attraction in the recommended list is matched with the rule. The preference probability of each attribute is weighted average, and the user's preference probability for tourist attractions is obtained. This value is multiplied by the preference probability for tourist attractions category, and the result obtained is the probability value of recommending a tourist attraction to the user.

\section{Personalized Recommendation of Smart Tourism Based on Big Data Technology}

In order to analyze the page reasonably and effectively, and accurately obtain the user's interest information, it is first necessary to normalize the web page. Secondly, the information content is extracted, and then the word segmentation tool is used to segment the extracted content, and finally the keyword set of each page is obtained. Figure 4 is the preprocessing flow of page information.

When updating, it is necessary to perform operations such as preprocessing and weight calculation on newly added web pages in the favorites and historical browsing records not in the favorites to establish the feature vector of the page. The regular update process is shown in Figure 5 [20].

It can be seen from Figure 6 that the realization of secondary sorting is mainly divided into the following steps. (1) The algorithm obtains the user's relevant information through different ways and then processes the obtained information. The algorithm uses the processed information to establish an initial interest model for the user and periodically updates the user's interest model to ensure the timeliness of the user's interest model. (2) The user retrieves keywords through the search platform, and the search platform obtains the pages of the result set for the first time and performs feature vector settlement for each of the top $n$ related web pages.

This article uses crawler tools and big data technology to build a smart tourism retrieval experiment platform. Its overall structure is shown in Figure 7.

The flow chart of the working principle of the crawler tool is shown in Figure 8.

After constructing the above model, the performance of the model is verified, and the effect of tourism data mining and the effect of intelligent personalized recommendation are evaluated, and the results are shown in Table 3 and Figure 9.

It can be seen from the above research that the intelligent tourism personalized recommendation system based on big data technology proposed in this paper has a high practical effect. 


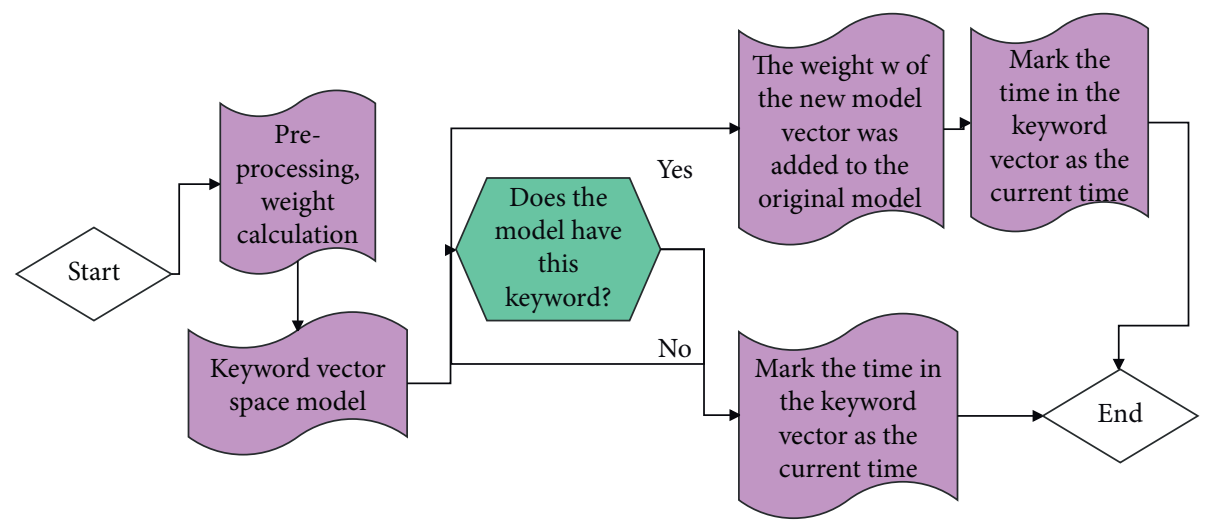

Figure 5: Scheduled update flow chart.

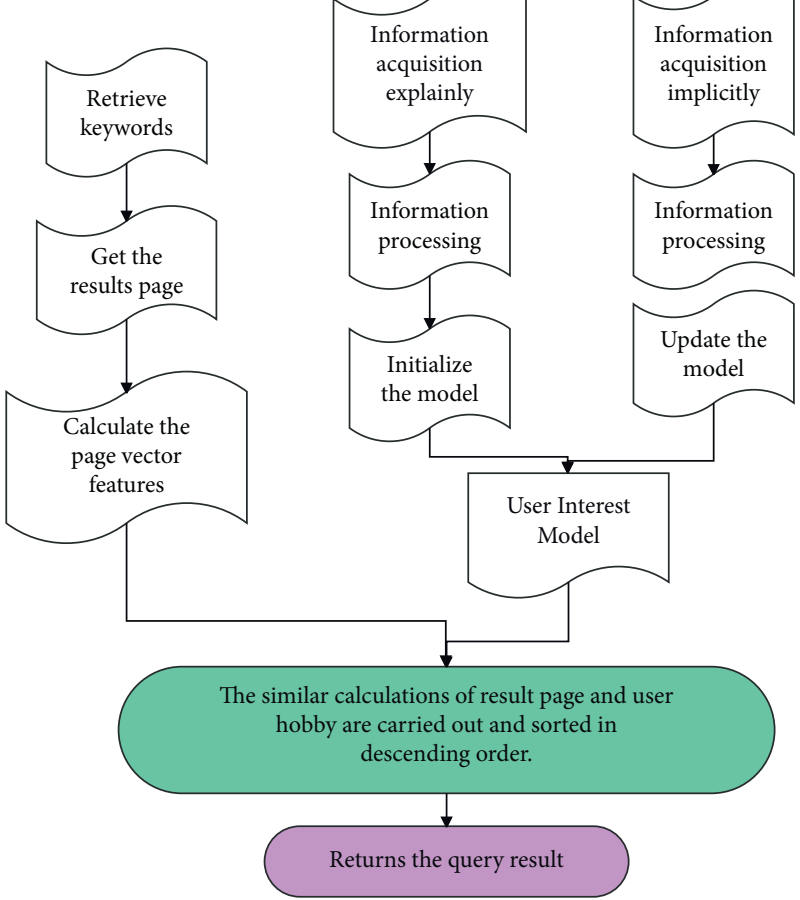

FIGURE 6: Secondary sorting diagram based on the interest model. 


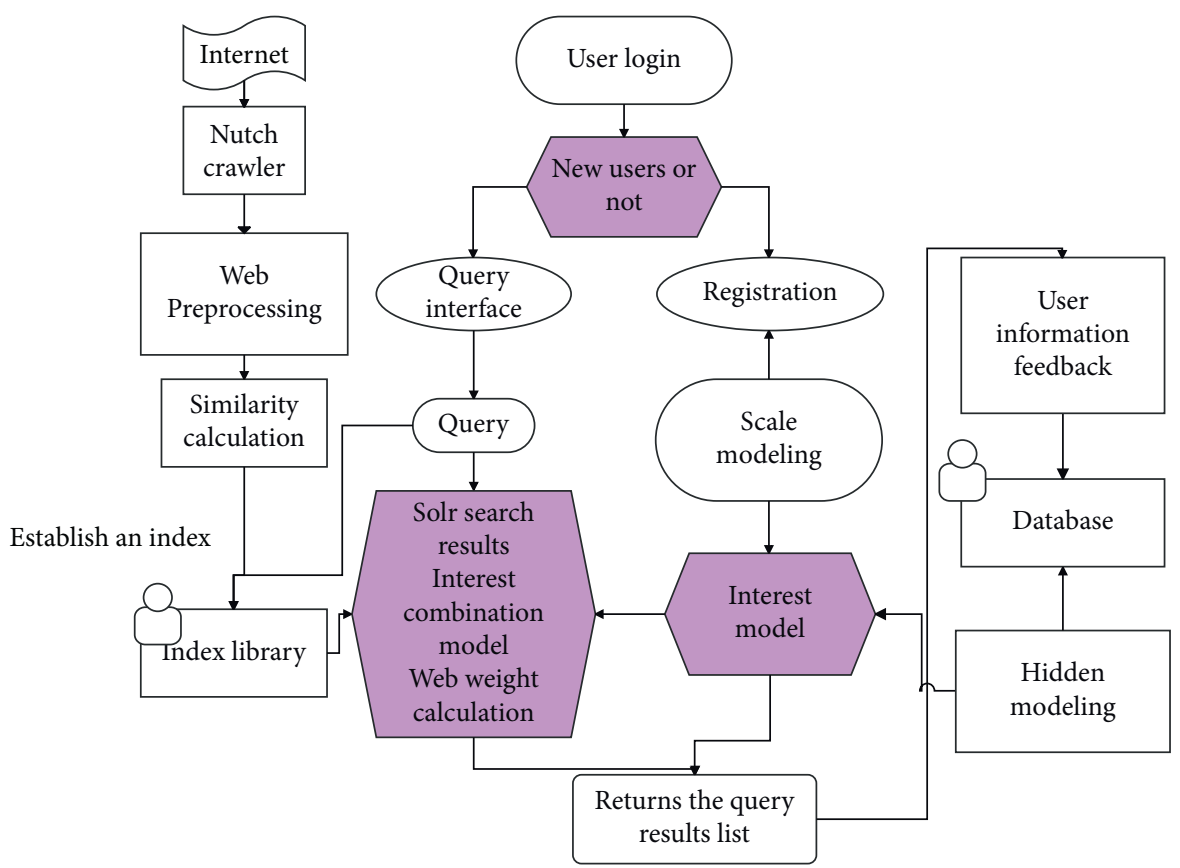

Figure 7: Overall architecture diagram of the platform.

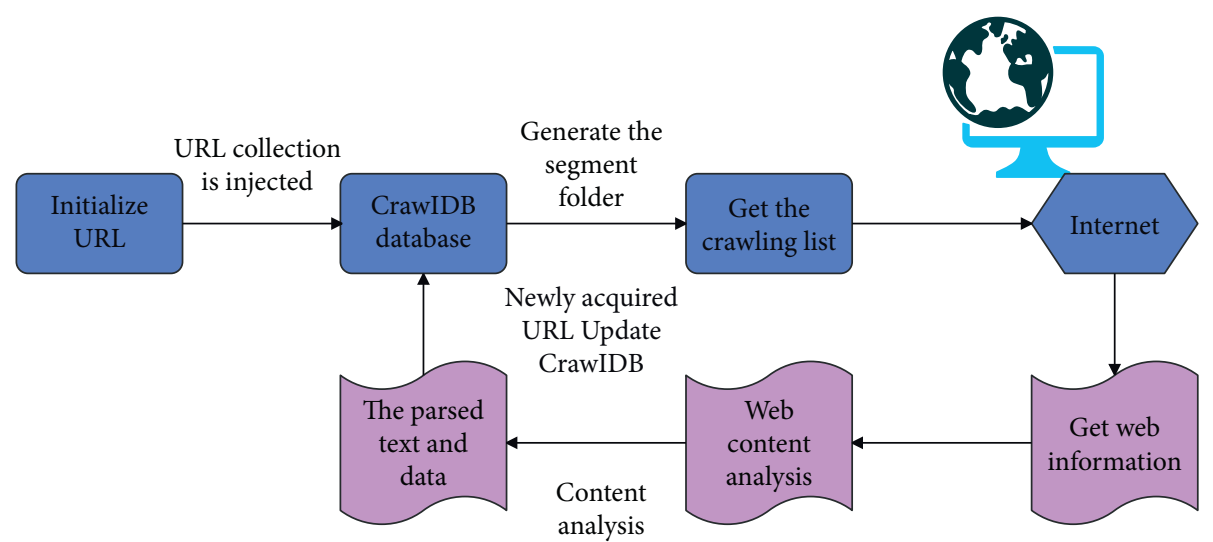

FIGURE 8: Working principle diagram of big data crawler.

TABLE 3: Experimental data of intelligent tourism personalized recommendation system based on big data technology.

\begin{tabular}{lcr}
\hline Number & Tourism data mining & Personalized recommendation \\
\hline 1 & 86.88 & 90.15 \\
2 & 81.99 & 90.03 \\
3 & 82.75 & 87.72 \\
4 & 81.64 & 76.53 \\
5 & 87.51 & 83.43 \\
6 & 81.57 & 83.02 \\
7 & 87.77 & 82.23 \\
8 & 84.06 & 84.04 \\
9 & 81.04 & 76.63 \\
10 & 86.03 & 87.09 \\
11 & 84.56 & 84.38 \\
12 & 84.45 & 79.84 \\
13 & 86.15 & 90.27 \\
14 & 84.40 & 87.66 \\
\hline
\end{tabular}




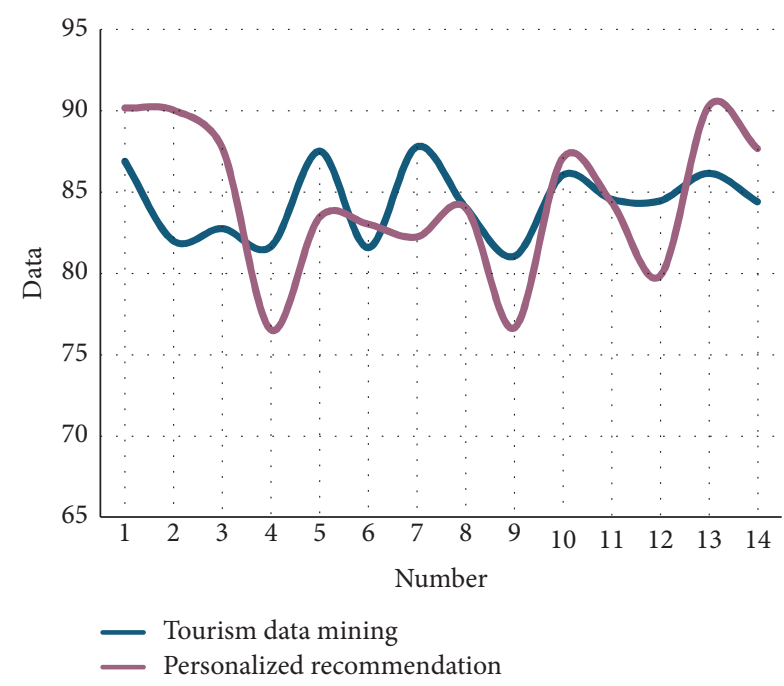

Figure 9: Performance statistics of smart tourism personalized recommendation system based on big data technology.

\section{Conclusion}

This paper analyzes and designs the recommendation subsystem in the tourism information recommendation system based on big data perception in detail. First of all, this paper models the contextual information usage ontology under the tourism information system and gives the association between the various ontologies. Then, this paper uses a matrix to describe each discrete attribute and interval attribute and uses a vector to model the user's preferences. After that, this paper proposes to use a rule-based recommendation algorithm, gives the framework of the recommendation system module, and then uses graphics to describe the entire process of the recommendation system and explains its process in detail. Finally, this paper introduces how to use rules to calculate and finally get a list of tourist attractions recommended to tourist users and combine experiments to verify the system of this paper. Through experimental analysis, it can be known that the intelligent tourism personalized recommendation system based on big data technology proposed in this paper has a high practical effect.

\section{Data Availability}

The labeled data sets used to support the findings of this study are available from the corresponding author upon request.

\section{Conflicts of Interest}

The author declares no conflicts of interest.

\section{Acknowledgments}

This study was sponsored by Xinyang Vocational and Technical College.

\section{References}

[1] K. Nam, C. S. Dutt, P. Chathoth, and M. S. Khan, "Blockchain technology for smart city and smart tourism: latest trends and challenges," Asia Pacific Journal of Tourism Research, vol. 26, no. 4, pp. 454-468, 2021.

[2] C. D. Huang, J. Goo, K. Nam, and C. W. Yoo, "Smart tourism technologies in travel planning: the role of exploration and exploitation," Information \& Management, vol. 54, no. 6, pp. 757-770, 2017.

[3] T. Brandt, J. Bendler, and D. Neumann, "Social media analytics and value creation in urban smart tourism ecosystems," Information \& Management, vol. 54, no. 6, pp. 703-713, 2017.

[4] A. K. Tripathy, P. K. Tripathy, N. K. Ray, and S. P. Mohanty, "iTour: the future of smart tourism: an IoT framework for the independent mobility of tourists in smart cities," IEEE Consumer Electronics Magazine, vol. 7, no. 3, pp. 32-37, 2018.

[5] E. Sigalat-Signes, R. Calvo-Palomares, B. Roig-Merino, and I. García-Adán, "Transition towards a tourist innovation model: the smart tourism destination," Journal of Innovation \& Knowledge, vol. 5, no. 2, pp. 96-104, 2020.

[6] H. Lee, J. Lee, N. Chung, and C. Koo, "Tourists' happiness: are there smart tourism technology effects?" Asia Pacific Journal of Tourism Research, vol. 23, no. 5, pp. 486-501, 2018.

[7] C. Koo, L. Mendes-Filho, and D. Buhalis, "Guest editorial," Tourism Review, vol. 74, no. 1, pp. 1-4, 2019.

[8] T. Zhang, C. Cheung, and R. Law, "Functionality evaluation for destination marketing websites in smart tourism cities," Journal of China Tourism Research, vol. 14, no. 3, pp. 263-278, 2018.

[9] M. A. C. Ruíz, S. T. Bohorquez, and J. I. R. Molano, "Colombian tourism: proposal app to foster smart tourism in the country," Advanced Science Letters, vol. 23, no. 11, pp. 10533-10537, 2017.

[10] W. Wang, N. Kumar, J. Chen et al., "Realizing the potential of the Internet of things for smart tourism with $5 \mathrm{G}$ and AI," IEEE Network, vol. 34, no. 6, pp. 295-301, 2020.

[11] I. Guerra, F. Borges, J. Padrão, J. Tavares, and M. H. Padrão, "Smart cities, smart tourism? the case of the city of porto," Revista Galega de Economia, vol. 26, no. 2, pp. 129-142, 2017.

[12] Y. Topsakal, M. Bahar, and N. Yüzbaşioğlu, "Review of smart tourism literature by bibliometric and visualization analysis," Journal of Tourism Intelligence and Smartness, vol. 3, no. 1, pp. 1-15, 2020.

[13] S. Joshi, "Social network analysis in smart tourism driven service distribution channels: evidence from tourism supply chain of Uttarakhand, India," International Journal of Digital Culture and Electronic Tourism, vol. 2, no. 4, pp. 255-272, 2018.

[14] F. Femenia-Serra, B. Neuhofer, and J. A. Ivars-Baidal, "Towards a conceptualisation of smart tourists and their role within the smart destination scenario," Service Industries Journal, vol. 39, no. 2, pp. 109-133, 2019.

[15] C. Koo, F. Ricci, C. Cobanoglu, and F. Okumus, "Special issue on smart, connected hospitality and tourism," Information Systems Frontiers, vol. 19, no. 4, pp. 699-703, 2017.

[16] H. Abdel Rady and A. Khalf, "Towards smart tourism destination: an empirical study on sharm el sheikh city, Egypt," International Journal of Heritage, Tourism and Hospitality, vol. 13, no. 1, pp. 78-95, 2019.

[17] T. Pencarelli, "The digital revolution in the travel and tourism industry," Information Technology \& Tourism, vol. 22, no. 3, pp. 455-476, 2020. 
[18] C. J. P. Abad and J. F. Álvarez, "Landscape as digital content and a smart tourism resource in the mining area of cartagenaLa unión (Spain)," Land, vol. 9, no. 4, pp. 1-22, 2020.

[19] P. M. da Costa Liberato, E. Alén-González, and D. F. V. de Azevedo Liberato, "Digital technology in a smart tourist destination: the case of porto," Journal of Urban Technology, vol. 25, no. 1, pp. 75-97, 2018.

[20] J.-J. Hew, G. W.-H. Tan, B. Lin, and K.-B. Ooi, "Generating travel-related contents through mobile social tourism: does privacy paradox persist?" Telematics and Informatics, vol. 34, no. 7, pp. 914-935, 2017. 